\title{
A study on the effect of IL-6 gene polymorphism on the prognosis of non-small-cell lung cancer
}

\author{
This article was published in the following Dove Press journal: \\ OncoTargets and Therapy \\ 23 September 2015 \\ Number of times this article has been viewed
}

Wei Jia

Guang-He Fei

Jie-Gui Hu

Xian-Wei Hu

Pulmonary Department, First Affiliated Hospital of Anhui Medical University, Hefei, People's Republic of China
Correspondence: Guang-He Fei Pulmonary Department, First Affiliated Hospital of Anhui Medical University, jixi Road 218\#, Hefei 230022, People's Republic of China

Tel +86 55I 629221 I4

Fax +8655 I 63633742

Email guanghefei@I26.com
Background: Lung cancer is one of the most commonly diagnosed clinical diseases. $I L-6$ is a multifunctional cytokine that is related to chemotactic factors and tumor biological regulation. $-174 \mathrm{G} / \mathrm{C}$ polymorphism in the promoter region of the $I L-6$ gene single-nucleotide polymorphism is the -174 position change from $\mathrm{G}$ to $\mathrm{C}$. However, the relationship between the $I L-6$ gene polymorphism and prognosis of lung cancer is elusive. Therefore, the aim of this study was to evaluate the effect of $-174 \mathrm{G} / \mathrm{C}$ polymorphism on the prognosis of patients with non-small-cell lung cancer (NSCLC).

Methods: DNA was extracted from the peripheral blood of 434 cases diagnosed with NSCLC by cytologic or histologic examination. Polymerase chain reaction-restriction fragment length polymorphism (NlaIII) was used to detect the genotype of $-174 \mathrm{G} / \mathrm{C}$. Based on the functional activity of the $I L-6$ gene polymorphism, genotypes were divided into G vector (CG/GG) (high yield) and CC genotype (low yield). Prognosis of patients was analyzed and independent risk factors evaluated. A quantitative analysis of the degree of pain after diagnosis was performed to evaluate the correlations between gene polymorphisms and the degree of pain and use of analgesics.

Results: Survival analysis showed that survival of the patients carrying the G allele (CG/GG) was significantly lower than that of patients with CC genotype (42.31 versus 62.79 months; $P=0.032$ ). The $I L-6$ gene promoter region revealed the presence of polymorphic variants, which may be associated with changes in the gene transcription process that affect the level of serum cytokines. IL-6 -174G/C gene polymorphism is associated with a significant morphine equivalent daily dose (IL-6 GG, 69.61; GC, 73.17; CC, 181.67; P=0.004). Homozygous $I L-6-174 \mathrm{C} / \mathrm{C}$ genotype carriers required higher doses of opioids than GG or GC carriers.

Conclusion: Polymorphism of $-174 \mathrm{G} / \mathrm{C}$ in $I L-6$ is closely related to cancer pain in NSCLC patients, the use of analgesics, and survival prognosis. It is necessary to further confirm the related results and determine the underlying pathogenic mechanisms.

Keywords: interleukin 6, NSCLC, survival rate

\section{Introduction}

Lung cancer is one of the most commonly diagnosed clinical diseases, accounting for $26 \%$ of all female cancer deaths and $29 \%$ of male cancer deaths. Non-small-cell lung cancer (NSCLC) accounts for approximately $85 \%$ of all lung cancers, and its course of disease is very severe, meaning a poor prognosis for patients. ${ }^{1,2}$ Clinical and epidemiological findings show that $20 \%$ of cancers are related to chronic infection; $30 \%$ are related to smoking and pollutant inhalation (eg, silicon dioxide and asbestos); and 35\% are related to diet (fat accounts $20 \%$ of diet). ${ }^{3}$ The lung cancer tumor microenvironment consists of extracellular matrix, tumor cells, desmocytes, inflammatory corpuscles, chemotactic factors, hormones, proteases, etc. Chemotactic factors are the basis of many biological metabolic processes which acts as an autocrine or paracrine growth factor 
in the process of tumor. $I L-6$ is a multifunctional cytokine that is related to chemotactic factors and tumor biological regulation. $I L-6$ participates in tumor cell proliferation, apoptosis, differentiation, and other important processes. In particular, it is expressed in malignant epithelial cells, so it is closely related to poor prognosis of cancer. ${ }^{4-6}$ The $I L-6$ gene is located on the 7 p21 chromosome. Some studies confirm that single-nucleotide polymorphism appears in the area of promoter -174 . The change from $\mathrm{G}$ to $\mathrm{C}$ in the position of -174 (rs1800795) is related to the rate of transcription of the $I L-6$ gene, which subsequently influences the level of IL-6 in peripheral circulation. Polymorphism forms two kinds of gene phenotype: the high-yielding type (located in the $-174 \mathrm{G} / \mathrm{G}$ and $-174 \mathrm{G} / \mathrm{C}$ gene vectors; the level of $I L-6$ is higher in peripheral circulation) and the low-yielding type (located in the $-174 \mathrm{C} / \mathrm{C}$ gene vector). ${ }^{7}$ Genetic research shows that there are some ethnic differences in the $-174 \mathrm{G}$ allele frequency. ${ }^{8}$ In the present study, the effect of $I L-6$ gene $-174 \mathrm{G} / \mathrm{C}$ polymorphism on the prognosis of patients with NSCLC is explored for the first time.

Pain is one of the most common and important factors affecting the prognosis of cancer patients. It is reported that the incidence of pain during the active phase is $30 \%-40 \%$, which will reach $80 \%$ in the terminal stage of cancer. Opioids are the first choice in the treatment of cancer pain, but the effects may vary widely among individuals. High doses of opioids lead to neuronal toxicity, and repeated usage will increase side effect and cause tolerance. Therefore, it is necessary to find a new marker to determine the sensitivity response of patients on opioids. The opioid tolerance is considered as the potential mechanisms of cancer pain. When inflammation or nerve damage exists in the body, activated neurons will release proinflammatory cytokines that can make the pain transmission neurons highly active. ${ }^{9}$ Synaptic front-end release of a lot of substance $\mathrm{P}$ and excitatory amino acids aggravates the pain reaction. ${ }^{10}$ This study takes these details as a starting point to explore the correlation between IL-6 -174G/C gene polymorphism and pain.

\section{Materials and methods General patient information}

The objects of study were patients who were diagnosed with NSCLC by histopathology between 1999 and 2012. There were 434 cases, and the average age was $63.00 \pm 10.25$ years. The inclusion criteria were NSCLC confirmed by histology or cytology and no antitumor therapy except relief of symptoms; a US Eastern Cooperative Oncology Group (ECOG) score of $\leq 2$ ( 0 means completely normal; 1 means a patient can walk but aggravating activities will be limited; 2 means a patient can walk and perform activities of daily living but cannot work); and no history of other tumors. Excluded were patients whose NSCLC tissue type information was lacking and patients who did not agree to enter the study. Smokers were defined as patients who were regular smokers when diagnosed. This study was approved by the ethics committee of The First affiliated hospital of Anhui Medical University, Hefei, China, and informed consent by patients and their family members was given for all the relevant procedures.

\section{IL-6 - I 74G/C genotype}

Standard EDTA tubes were used to obtain blood samples, and DNA was obtained from each patient's white blood cells using the QIAmp ${ }^{\circledR}$ DNA Blood Mini Kit. The blood samples were collected from patients during clinical evaluation. The DNA was extracted and analyzed by polymerase chain reaction (PCR) assay during the patient's evaluation. After restriction fragment length polymorphism processing, $I L-6-174 \mathrm{G} / \mathrm{C}$ polymorphism was analyzed using PCR (Figure 1). The primers for polymorphism analysis was used with the standard primers. Digest 164 bp products of PCR was completed at the condition of 5 units NlaIII (New England Biolabs) at $37^{\circ} \mathrm{C}$ for 4 hours. Restriction fragments were analyzed using 3\% ethidium bromide-stained agarose gel. The 111- and 52-position fragments are consistent with the homozygous genotype $\mathrm{C} / \mathrm{C}$; $164 \mathrm{bp}$ represents the homozygous genotype $\mathrm{G} / \mathrm{G}$. The three fragments in the positions of 111,52 , and $164 \mathrm{bp}$ represent the heterozygous genotype $\mathrm{G} / \mathrm{C}$. The reliability of samples was analyzed and evaluated. A negative control was used to prevent false positive results.

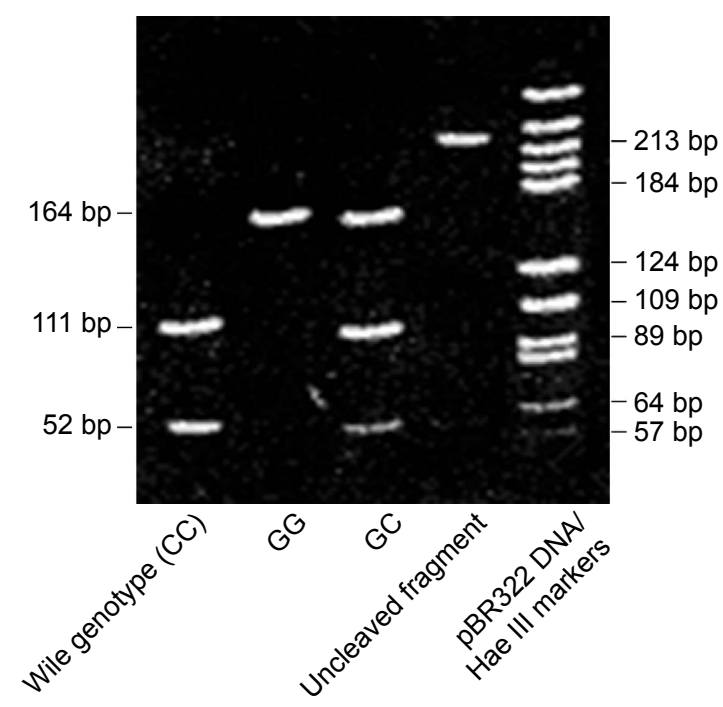

Figure I Image of agarose gel fragments of genotypes. 


\section{Cancer pain quantification and the use of opioids}

Patient treatment information and follow-up data were obtained and the pain after diagnosis quantified. The cancer pain quantification was performed by using the Global Pain Score (GPS). The GPS ranges from 0 to 10 points ( 0 points means no pain at all; 10 points means the pain is unbearable). The detailed cancer pain quantification was performed according to the methods of Banerjee et al. ${ }^{11}$ At the same time, the daily use of opioids among patients after diagnosis was recorded. The opioid treatment process was as described in Banerjee et al's report. ${ }^{11}$ Finally, the doses of the different kinds of opioids were converted to morphine equivalent daily dose (MEDD) for analysis. If a patient's medical records were incomplete, we obtained the relevant data by telephone interview or other methods.

\section{Statistical analysis}

SPSS software (version 19.0; IBM Corporation, Armonk, NY, USA) was used to analyze data. The data were evaluated using the $\chi^{2}$ test or Fisher's exact test. The survival distribution of patients was evaluated using the Kaplan-Meier curve. The survival time analysis included only those patients who were still alive at the time of analysis. Life cycle was defined as the timespan from the time of diagnosis to death or final evaluation. Multivariate Cox proportional model was used to analyze and compare age, sex, tumor stage, tissue type, smoking history, and correlation between $I L-6$ genotype and the total NSCLC survival rate. Risk ratios and 95\% credibility intervals (CIs) describe the related risk factors. Multivariate regression analysis was used to evaluate whether IL-6 -174G/C genotype was related to the degree of pain and the use of opioids. A $P$-value $<0.05$ indicated the difference was statistically significant.

\section{Results}

\section{Basic statistics of the patients}

Blood samples were obtained from 434 cases diagnosed with NSCLC. Before treatment, we divided them according to carcinoma type: 165 cases had epidermoid carcinoma, 207 cases adenocarcinoma, 40 cases undifferentiated carcinoma, 14 cases large-cell carcinoma, and five cases mixed carcinoma; $78.11 \%$ were male and $21.43 \%$ were female. Smokers accounted for $72.12 \%$ (Table 1). The genotype frequencies of $\mathrm{GG}, \mathrm{GC}$, and $\mathrm{CC}$ were $37.6 \%, 54.9 \%$, and $7.5 \%$, respectively.

Based on the functional activity, we divided the patients into two IL-6 polymorphism groups: a high-yielding group
Table I Basic data of patients (434 cases)

\begin{tabular}{lll}
\hline Characteristics & $\mathbf{N}$ & Percentage \\
\hline Sex & 339 & 78.11 \\
Male & 93 & 21.43 \\
Female & 2 & 0.46 \\
$\quad$ No information & $63.00 \pm 10.25$ & \\
Age, years (mean \pm standard & & \\
deviation) & & \\
Histology & 165 & 38.02 \\
Epidermoid carcinoma & 207 & 47.70 \\
Adenocarcinoma & 40 & 9.22 \\
Undifferentiated carcinoma & 14 & 3.22 \\
Large-cell carcinoma & 5 & 1.15 \\
Mixed-type carcinoma & 3 & 0.69 \\
No information & & \\
Tumor stage & 46 & 10.60 \\
Stage I & 31 & 7.14 \\
Stage II & 192 & 44.24 \\
Stage III & 162 & 37.33 \\
Stage IV & 3 & 0.69 \\
No information & & \\
Smoking history & 313 & 72.12 \\
Smoker & 114 & 26.27 \\
Nonsmoker & 7 & 1.61 \\
No information & & \\
Cancer pain quantification & 245 & 56.5 \\
Global Pain Score $<5$ & & \\
Global Pain Score $\geq 5$ & & \\
\hline
\end{tabular}

(G genotype, increased expression of $I L-\sigma$ ) and a lowyielding group (CC, low expression of $I L-6)$. We found that expression frequency of the $\mathrm{G}$ genotype was approximately 92.5\%. Compared with the age of patients when they were diagnosed $(P=0.367)$, tissue type $(P=0.470)$, sex $(P=0.761)$, smoking history $(P=0.196)$, and tumor stage $(P=0.238)$, there was no obvious difference in the genotypes ( $\mathrm{CC}$ and $\mathrm{G}$ carrier) among the groups.

\section{IL-6 - I74G/C polymorphism analysis}

The overall survival rate of the patients was analyzed using Kaplan-Meier methodology, and the results show that, according to $I L-6-174 \mathrm{G} / \mathrm{C}$ polymorphism, there are some obvious differences between the mean survival rates of NSCLC patients. The survival time of patients who carried the $\mathrm{G}$ allele $(\mathrm{GG} / \mathrm{GC})$ was obviously lower than that of the patients who carried the CC genetype (42.31 months versus 62.79 months; $P=0.032$ ) (Figure 2).

\section{Regression analysis of overall survival prognosis}

In order to further determine the effect of $I L-6-174 \mathrm{G} / \mathrm{C}$ polymorphism on overall survival, we used the Cox proportional 


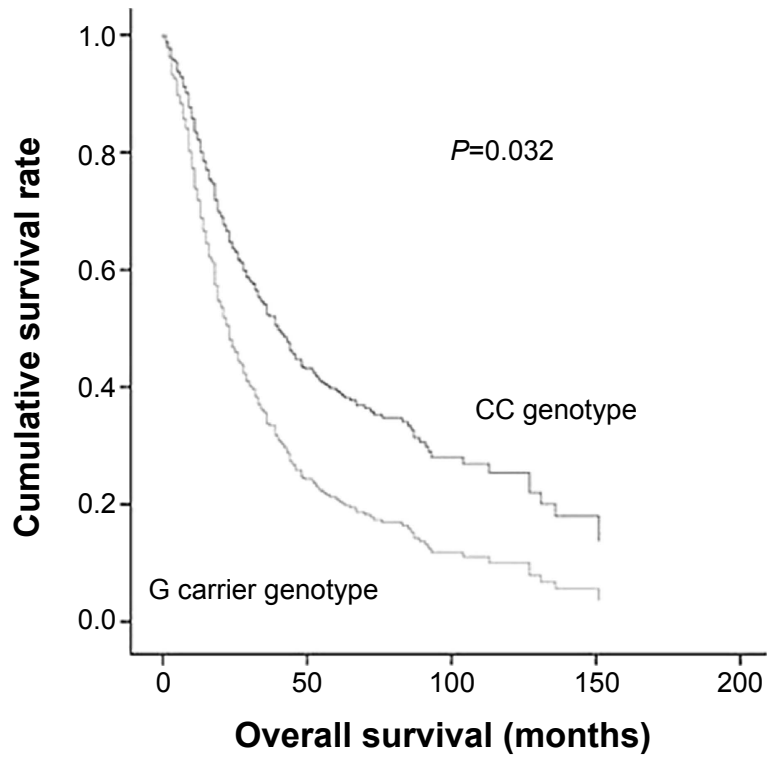

Figure 2 Overall survival analysis of patients.

Notes: The overall survival rate and distribution were analyzed using the KaplanMeier curve. Kaplan-Meier survival curves and logrank test were used to determine the $P$-value.

hazards model to analyze sex, age, tumor stage, pathologic type, smoking history, and other correlation variables. We found that tumor stage $(P<0.001)$, smoking history $(P=0.049)$, and $I L-6-174 \mathrm{G} / \mathrm{C}$ polymorphism $(P=0.022)$ were the independent prognostic factors of overall survival in the patients with NSCLC (Table 2).

\section{Correlation between IL-6 - I74G/C polymorphism and pain}

We defined $\geq 7$ points on GPS as severe pain. The data show that $41 \%$ of patients had severe pain when diagnosed. After diagnosis, the average MEDD was $>120 \mathrm{mg} / 24$ hours. Univariate analysis of all samples showed that $I L-6-174 \mathrm{G} / \mathrm{C}$ gene polymorphism was significantly related to MEDD (IL-6 GG, 69.61; GC, 73.17; CC, 181.67; $P=0.004$ ) (Table 3). After stratifying by sex, the correspondence between the different

Table 2 Multivariate Cox regression analysis of the overall survival rate prediction factors

\begin{tabular}{llll}
\hline & $\begin{array}{l}\text { Hazard } \\
\text { ratio }\end{array}$ & $\begin{array}{l}\text { 95\% credibility } \\
\text { interval }\end{array}$ & P-value \\
\hline IL-6 - I74G/C & 1.682 & $1.077-2.628$ & 0.022 \\
Sex & 0.964 & $0.668-1.391$ & 0.844 \\
Age ( $\geq 63$ years, & 0.982 & $0.788-1.224$ & $0.87 \mathrm{I}$ \\
$<63$ years) & & & \\
Smoking history & 1.423 & $1.00 \mathrm{I}-2.024$ & 0.049 \\
Histology & 0.933 & $0.810-1.074$ & 0.336 \\
Tumor stage & 2.470 & $1.969-3.099$ & $<0.00 \mathrm{I}$ \\
\hline
\end{tabular}

IL-6 genotypes and MEDD was more obvious for male than for female patients. In addition, the required dose for $\mathrm{CC}$ genotype patients was the highest. Multivariate logistic regression analysis also showed that the required opioid dose for homozygous $I L-6-174 \mathrm{C} / \mathrm{C}$ genotype carriers was higher than for $\mathrm{GG}$ or $\mathrm{GC}$ carriers (odds ratio $=4.7$; 95\% CI: 1.2-15.0).

\section{Discussion}

The latest study shows that mediators of inflammation can promote the progress of various tumor pathologies, including lung cancer. Previous findings have shown that $I L-6-174 \mathrm{G} / \mathrm{C}$ polymorphism is related to the risk factors of lung cancer. ${ }^{12}$ Therefore, the aim of this study was to explore the effect of $I L-6$ gene $-174 \mathrm{G} / \mathrm{C}$ polymorphism on the prognosis of patients with lung cancer.

$I L-6$ is a kind of cell factor that plays an important role in tumor cells. It is involved in many metabolic processes, such as differentiation of malignant tumor cells, tumor growth, and the regulation of the immune microenvironment. It can also promote angiogenesis, inhibit apoptosis, and increase the cells resistant. $I L-6$ is a direct stimulation factor that promotes tumor growth by the activation of multiple signaling pathways, for example, by activating the Ras/ Raf/MEK/ERK1/2 pathway to promote the proliferation of tumor cells. ${ }^{13,14}$ On the other hand, it also activates STAT3, which promotes upregulation of cyclin D1, D2, and B1 and Myc and downregulation of CDK inhibitory factor $\mathrm{p} 21^{\mathrm{Cip} 1}$ to promote cells into the cell cycle. ${ }^{15,16}$

Excessive expression of $I L-6$ in lung, brain, liver, and other specific organs can lead the peripheral circulating tumor cells into such organs and promote the metastasis of tumor. ${ }^{17}$ In recent years, it has been confirmed that $I L-6$ and IL-8 cytokines can increase tumor cells from the counts primary cancers and to the circulation - a process called "tumor self cultivation" - and can accelerate tumor growth, vascularization, and stromal cell recruitment. ${ }^{18-20}$ Many studies have shown that high levels of $I L-6$ in serum are related to the clinical prognosis of breast cancer, prostate cancer, pancreatic cancer, ovarian cancer, and other cancers. A study by Crohns et $\mathrm{al}^{12}$ has shown that $I L-6$ and other cytokines may have a certain prognosis function in patients with lung cancer survival. The previous studies state that there are high levels of IL-6, IL-10, IL-12, and TNF-alpha in serum, and being black or white are associated with lung cancer prognosis, so it can be concluded that the peripheral high levels of circulating $I L-6$ are related to the need for chemotherapy in NSCLC patients with poor response and poor clinical prognosis. ${ }^{21,22}$ 
Table 3 Correlations between IL-6 - I74G/C gene polymorphisms and the degree of pain or MEDD

\begin{tabular}{|c|c|c|c|c|c|c|}
\hline \multirow[t]{2}{*}{ Genotype } & \multicolumn{3}{|l|}{ Pain degree } & \multicolumn{3}{|l|}{ MEDD } \\
\hline & $\begin{array}{l}\text { Total, mean } \\
\text { (SD) }\end{array}$ & $\begin{array}{l}\text { Males, mean } \\
\text { (SD) }\end{array}$ & $\begin{array}{l}\text { Females, } \\
\text { mean (SD) }\end{array}$ & $\begin{array}{l}\text { Total, mean } \\
\text { (SD) }\end{array}$ & $\begin{array}{l}\text { Males, mean } \\
\text { (SD) }\end{array}$ & $\begin{array}{l}\text { Females, mean } \\
\text { (SD) }\end{array}$ \\
\hline \multicolumn{7}{|l|}{ IL-6 - I74G/C } \\
\hline GG & $5.00(3.20)$ & $4.68(3.21)$ & $5.40(3.21)$ & 69.61 (77.4) & 72.89 (83.92) & $64.81(68.06)$ \\
\hline GC & $4.30(2.8 I)$ & $5.43(3.18)$ & $3.47(2.24)$ & 73.17 (93.6) & $75.56(117.90)$ & 71.30 (7I.97) \\
\hline $\mathrm{CC}$ & $3.42(1.86)$ & $3.67(2.5)$ & $3.40(0.894)$ & $181.67(228.0)$ & 235.7I (I07.39) & $106.00(98.38)$ \\
\hline$G C+C C$ & $4.11(2.98)$ & $4.9(3.04)$ & $3.46(2.02)$ & $97.7(140.0)$ & 120.40 (I88.19) & 77.5 (76.40) \\
\hline $\begin{array}{l}\text { Odds ratio } \\
(95 \% \mathrm{Cl})\end{array}$ & $1.5(1.2-1.9)$ & $1.3(1.1-1.7)$ & $1.7(1.4-2.4)$ & $1.2(0.9-1.6)$ & I.I (0.8-I.5) & $1.4(1.1-2.5)$ \\
\hline$P$ & 0.067 & 0.053 & 0.075 & 0.004 & 0.0023 & 0.0055 \\
\hline
\end{tabular}

Abbreviations: $\mathrm{Cl}$, credibility interval; MEDD, morphine equivalent daily dose; SD, standard deviation.

The $I L-6$ promoter region polymorphism variant makes gene transcription change, which further influences the levels of cytokines in serum. -174G/C polymorphism in IL-6 replaces guanine with cytosine, and a correlation of the $\mathrm{G}$ allele with cancer and many other diseases has been confirmed. ${ }^{23}$ Therefore, we focused on the $I L-6-174 \mathrm{G} / \mathrm{C}$ polymorphism in the present study.

Some research suggests certain existing correlations between $I L-6$ level and lung cancer prognosis ${ }^{24}$ but, to the best of our knowledge, the present study explores the correlation between the $I L-6$ promoter region $-174 \mathrm{G} / \mathrm{C}$ gene polymorphism and the prognosis of survival for patients with NSCLC for the first time. Our results show that the overall survival stage ( $<20$ months) of the patients with NSCLC with the G genotype vector $(\mathrm{GG} / \mathrm{CG})$ was significantly lower than that of the $\mathrm{CC}$ genotype carriers $(P=0.032)$. Multivariate $\mathrm{Cox}$ proportional analysis showed that genetic mutations play an important role in the prognosis of patients with NSCLC in the survival period (risk ratio: 1.680; 95\% CI: 1.075-2.624; $P=0.023)$. Another possible explanation for the results is the expression of $I L-6$ regulatory CYP enzymes, including CYP1A1 and CYP1B1, which can activate heterocyclic amines and PAHs and other carcinogens. CYP1B1 clearly has excessive expression in lung cancer, colon cancer, breast cancer, and many other tumors. A previous study confirms that $I L-6$ inhibited including DNA methylation of miR27b expression, and expounds the related epigenetic matrix, so that expression of CYP1B1 is in upregulation. ${ }^{23} I L-6$ can induce colon cancer cell phenotypes to change and may cause resistance to drug and stimulate metabolism of carcinogens in situ, which leads to DNA damage and tumor invasiveness enhancement. $^{25,26}$

Data from preclinical studies have suggested that differences in $I L-6$ genotype may affect the use of opioid analgesics. Bianchi et $\mathrm{al}^{27}$ found that the analgesic effect on knockout $I L-6$ mice was abated; at the same time, $I L-6$ knockout mice were prone to analgesic drug tolerance. $I L-6$ genes located on chromosome $7 \mathrm{p} 21$ and $I L-6-174 \mathrm{G} / \mathrm{C}$ polymorphism affect transcription and change levels of $I L-6$ in serum. In this study, we initially found a correlation between the $I L-6$ gene and cancer pain in patients with NSCLC; a homozygous allele in patients with lower levels of serum $I L-6$ means the opioid dose required is significantly higher than in patients with other genotypes. At the same time, the male $I L-6-174 \mathrm{C} / \mathrm{C}$ patients required the highest analgesic drug doses; therefore, $I L-6$ gene polymorphism in patients with NSCLC may be a preliminary prediction for patients who are sensitive to the reactions of opioid analgesics; after detection in clinical practice, the treatment program can be adjusted in the initial stage of treatment, improving the quality of life and survival prognosis.

Though this study provides some valuable data and conclusions, there are limitations. First, we did not distinguish between pain from tumor growth and pain secondary to treatment toxicity. In future study, we will elaborate on the difference between pain from tumor growth and pain secondary to treatment toxicity and investigate the relationships between $I L-6$ polymorphism and the pain or the age of the patients. Second, potential associations of $I L-6$ polymorphism with survival were not investigated in the present study. In future, we will investigate the potential correlation between $I L-6$ polymorphism and progression-free survival. Furthermore, detailed explanations of $I L-6$-related development of pain will also be investigated.

\section{Conclusion}

$-174 \mathrm{G} / \mathrm{C}$ polymorphism in $I L-6$ is closely related to cancer pain in NSCLC patients, the use of analgesics, and survival prognosis. It is necessary to further confirm the related results and determine the underlying pathogenic mechanisms. 


\section{Disclosure}

The authors report no conflicts of interest in this work.

\section{References}

1. Jemal A, Bray F, Center MM, Ferlay J, Ward E, Forman D. Global cancer statistics. CA Cancer J Clin. 2011;61(2):69-90.

2. Babu KG, Prabhash K, Vaid AK, et al. Nimotuzumab plus chemotherapy versus chemotherapy alone in advanced non-small-cell lung cancer: a multicenter, randomized, open-label Phase II study. Onco Targets Ther. 2014; 7:1051-1060.

3. Molina JR, Yang P, Cassivi SD, Schild SE, Adjei AA. Non-small cell lung cancer: epidemiology, risk factors, treatment, and survivorship. Mayo Clin Proc. 2008;83(5):584-594.

4. Coussens LM, Werb Z. Inflammation and cancer. Nature. 2002;420(6917): 860-867.

5. Lin WW, Karin M. A cytokine-mediated link between innate immunity, inflammation, and cancer. J Clin Invest. 2007;117(5):1175-1183.

6. Aggarwal BB, Vijayalekshmi RV, Sung B. Targeting inflammatory pathways for prevention and therapy of cancer: short-term friend, long-term foe. Clin Cancer Res. 2009;15(2):425-430.

7. Chamorro A, Revilla M, Obach V, Vargas M, Planas AM. The -174G/C polymorphism of the interleukin 6 is a hallmark of lacunar stroke and not other ischemic stroke phenotypes. Cerebrovasc Dis. 2005;19(2): 91-95.

8. Brandao GD, Brega EF, Spatz A. The role of molecular pathology in non-small-cell lung carcinoma-now and in the future. Curr Oncol. 2012; 19(Suppl 1):S24-S32.

9. Cekanaviciute E, Dietrich HK, Axtell RC, et al. Astrocytic TGF- $\beta$ signaling limits inflammation and reduces neuronal damage during central nervous system Toxoplasma infection. J Immunol. 2014;193(1): 139-149.

10. Okano K, Kuraishi Y, Satoh M. Involvement of spinal substance $P$ and excitatory amino acids in inflammatory hyperalgesia in rats. Jpn J Pharmacol. 1998;76(1):15-22.

11. Banerjee M, Pal S, Bhattacharya B, Ghosh B, Mondal S, Basu J. A comparative study of efficacy and safety of gabapentin versus amitriptyline as coanalgesics in patients receiving opioid analgesics for neuropathic pain in malignancy. Indian J Pharmacol. 2013;45(4):334-338.

12. Crohns M, Saarelainen S, Laine S, Poussa T, Alho H, KellokumpuLehtinen P. Cytokines in bronchoalveolar lavage fluid and serum of lung cancer patients during radiotherapy - association of interleukin- 8 and VEGF with survival. Cytokine. 2010;50(1):30-36.
13. Ara T, Declerck YA. Interleukin-6 in bone metastasis and cancer progression. Eur J Cancer. 2010;46(7):1223-1231.

14. Naka T, Nishimoto N, Kishimoto T. The paradigm of IL-6: from basic science to medicine. Arthritis Res. 2002;4 Suppl 3:S233-S242.

15. Łukaszewicz M, Mroczko B, Szmitkowski M. [Clinical significance of interleukin-6 (IL-6) as a prognostic factor of cancer disease]. Pol Arch Med Wewn. 2007;117(5-6):247-251. Polish.

16. Giri D, Ozen M, Ittmann M. Interleukin-6 is an autocrine growth factor in human prostate cancer. Am J Pathol. 2001;159(6):2159-2165.

17. Culig Z, Steiner H, Bartsch G, Hobisch A. Interleukin-6 regulation of prostate cancer cell growth. J Cell Biochem. 2005;95(3):497-505.

18. Giannitrapani L, Soresi M, Balasus D, Licata A, Montalto G. Genetic association of interleukin-6 polymorphism $(-174 \mathrm{G} / \mathrm{C})$ with chronic liver diseases and hepatocellular carcinoma. World J Gastroenterol. 2013; 19(16):2449-2455.

19. Hefler LA, Grimm C, Ackermann S, et al. An interleukin-6 gene promoter polymorphism influences the biological phenotype of ovarian cancer. Cancer Res. 2003;63(12):3066-3068.

20. Zhang X, Yin P, DI D, et al. IL-6 regulates MMP-10 expression via JAK2/STAT3 signaling pathway in a human lung adenocarcinoma cell line. Anticancer Res. 2009;29(11):4497-4501.

21. Zarogoulidis P, Yarmus L, Darwiche K, et al. Interleukin-6 cytokine: a multifunctional glycoprotein for cancer. Immunome Res. 2013;9(62): 16535.

22. Liu RY, Song X, Chen P, et al. Association between IL6 -174G/C and cancer: a meta-analysis of 105,482 individuals. Exp Ther Med. 2012;3(4): 655-664.

23. Pine SR, Mechanic LE, Enewold L, et al. Increased levels of circulating interleukin 6, interleukin 8, C-reactive protein, and risk of lung cancer. J Natl Cancer Inst. 2011;103(14):1112-1122.

24. Cox ED, Hoffmann SC, DiMercurio BS, et al. Cytokine polymorphic analyses indicate ethnic differences in the allelic distribution of interleukin-2 and interleukin-6. Transplantation. 2001;72(4):720-726.

25. Meenagh A, Williams F, Ross OA, et al. Frequency of cytokine polymorphisms in populations from western Europe, Africa, Asia, the Middle East and South America. Hum Immunol. 2002;63(11):1055-1061.

26. Yang M, Li C, Li M. Association of interleukin-6 (-174 G/C) polymorphism with the prostate cancer risk: a meta-analysis. Biomed Rep. 2014; 2(5):637-643.

27. Bianchi M, Maggi R, Pimpinelli F, et al. Presence of a reduced opioid response in interleukin-6 knock out mice. Eur J Neurosci. 1999;11(5): 1501-1507.
OncoTargets and Therapy

\section{Publish your work in this journal}

OncoTargets and Therapy is an international, peer-reviewed, open access journal focusing on the pathological basis of all cancers, potential targets for therapy and treatment protocols employed to improve the management of cancer patients. The journal also focuses on the impact of management programs and new therapeutic agents and protocols on
Dovepress

patient perspectives such as quality of life, adherence and satisfaction. The manuscript management system is completely online and includes a very quick and fair peer-review system, which is all easy to use. Visit http://www.dovepress.com/testimonials.php to read real quotes from published authors. 